Case Report

\title{
A Scaphoid Stress Fracture in a Female Collegiate-Level Shot-Putter and Review of the Literature
}

\author{
Jessica M. Kohring, ${ }^{1}$ Heather M. Curtiss, ${ }^{2}$ and Andrew R. Tyser ${ }^{1}$ \\ ${ }^{1}$ Department of Orthopaedic Surgery, University of Utah, Salt Lake City, UT 84108, USA \\ ${ }^{2}$ Marshfield Clinic, Department of Sports Medicine, Physical Medicine \& Rehabilitation, \\ University of Wisconsin-Stevens Point, Marshfield, WI 54449, USA \\ Correspondence should be addressed to Jessica M. Kohring; jessica.kohring@hsc.utah.edu
}

Received 6 April 2016; Accepted 26 June 2016

Academic Editor: Bayram Unver

Copyright ( $) 2016$ Jessica M. Kohring et al. This is an open access article distributed under the Creative Commons Attribution License, which permits unrestricted use, distribution, and reproduction in any medium, provided the original work is properly cited.

Scaphoid stress fractures are rare injuries that have been described in young, high-level athletes who exhibit repetitive loading with the wrist in extension. We present a case of an occult scaphoid stress fracture in a 22-year-old female Division I collegiate shotputter. She was successfully treated with immobilization in a thumb spica splint for 6 weeks. Loaded wrist extension activities can predispose certain high-level athletes to sustain scaphoid stress fractures, and a high index of suspicion in this patient population may aid prompt diagnosis and management of this rare injury.

\section{Introduction}

Scaphoid fractures are common in young adults and athletes and can lead to significant morbidity even with early diagnosis and appropriate treatment. While scaphoid fractures are most commonly associated with acute wrist trauma, it is notable that chronic repetitive loaded wrist extension can lead to scaphoid stress fractures [1].

Although rare, scaphoid stress fractures have been described in young, high-level athletes who exhibit repetitive loading with the wrist in extension, most commonly in gymnasts [2-7]. With increasing participation in high-level athletics at an earlier age, there has been a perceived increase in the incidence of pediatric and young adult stress fractures occurring in the upper extremity [5,8]. Given the wellrecognized challenges in diagnosing and managing scaphoid fractures, prompt recognition of these injuries-both acute and chronic varieties-is critical. Here we present a case of an occult scaphoid stress fracture in a 22 -year-old female Division I collegiate shot-putter who was successfully treated nonsurgically and returned to sport.

\section{Case Report}

A 22-year-old female Division I collegiate right-hand dominant shot-putter initially presented with a two-month history of progressive, activity-related right wrist pain, with no report of prior trauma. She noted worsening pain with wrist extension during throwing the shot-put but had no complaints of pain or dysfunction with the discus nor with activities of daily living. The patient had been training for three to four hours per day, five times per week, alternating between the shot-put and discus as well as doing Olympicstyle weight lifting for seven years prior to presentation.

Physical exam revealed tenderness to palpation at the anatomic snuffbox and the scaphoid tuberosity. Wrist flexion, extension, and supination were symmetric, but painful with loaded terminal extension in the dominant wrist. Radiographs of the affected wrist at the time of presentation, demonstrated $-1 \mathrm{~mm}$ ulnar negative variance, with no evidence of abnormality (Figures 1, 2, and 3). Due to a high level of suspicion, a noncontrast 1.5-Tesla MRI of the wrist was obtained. The MRI demonstrated an incomplete stress 


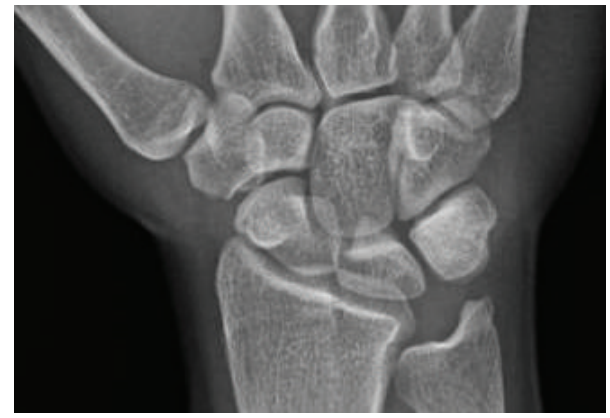

FIGURE 1: Posteroanterior radiographic view of the wrist at the time of initial evaluation that shows no abnormality in the scaphoid.

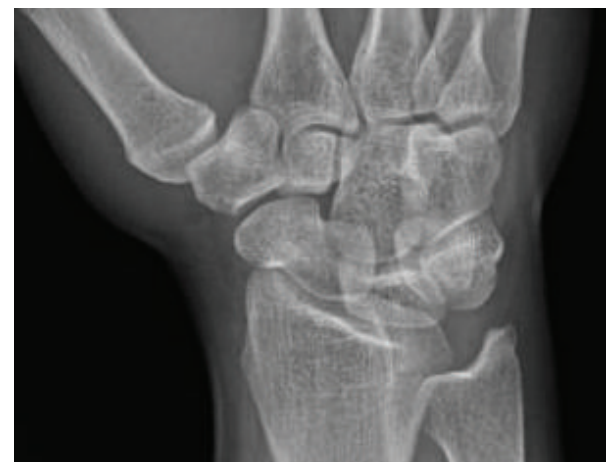

Figure 2: An oblique radiographic view at the time of initial evaluation without evidence of abnormality of the scaphoid.

fracture at the scaphoid waist with associated bone edema and no cortical breakthrough, best seen on the T2 sagittal cut (Figure 4).

The patient was placed in a removable thumb spica wrist splint and was instructed to avoid any loaded extension of the wrist, including throwing the shot-put and weight-training. She was allowed to throw discus as it did not cause any pain. After three weeks, the patient reported no symptoms or pain with wrist extension. Radiographs obtained at 6 weeks after thumb spica immobilization were negative for any evidence of scaphoid fracture (Figures 5, 6, and 7). On physical exam, the patient had no tenderness to palpation in the anatomic snuffbox. The patient was released back to full activity without restrictions and returned to full participation in Division I shot-put without symptoms thereafter. At followup three years after her diagnosis, she reported no pain and no limitations in wrist or hand use.

\section{Discussion}

Scaphoid stress fractures are very rare injuries, with only case reports available for analysis in the peer-reviewed literature. In each reported case, the patients were competitive, highlevel athletes training for multiple hours per day for several years prior to their presentation (Table 1). While gymnasts have been the athletes most commonly affected [2-7], others have also experienced these rare injuries: divers, soccer

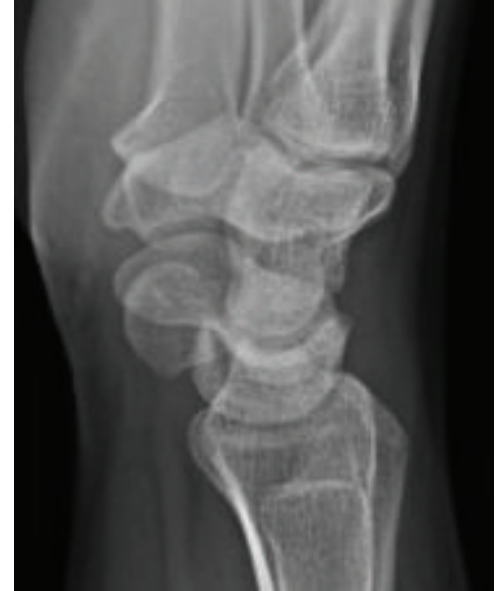

FIGURE 3: A lateral view of the wrist at the time of initial evaluation without radiographic abnormality of the scaphoid.

goalkeepers, shot-putters, badminton, cricket, and tennis players [3, 9-16].

Common to all of these athletic activities is the act of repetitive loaded wrist extension. Although the exact factors that lead to stress fractures of the scaphoid remain unclear, it has been suggested that repetitive stress and microtrauma to the bone can exceed native osseous repair mechanisms [3]. In each clinical case of a scaphoid stress fracture reported in the literature to date, including this one, the scaphoid waist was the location of the stress fracture.

Loaded wrist extension creates stresses that are typically centered at the scaphoid waist. In a cadaver study, Weber and Chao reported that 460 to 960 pounds of force applied to an extended wrist was required to acutely fracture the scaphoid, at the waist [17]. A more recent biomechanical study performed by Majima et al. found that loading the wrist in extension transmits force primarily through the scaphoid waist [18]. Handstands and other static maneuvers that require maximum wrist extension have been reported to exert considerable force across the scaphoid waist, but not to the extent needed to cause acute fracture [17].

Interestingly, the majority of scaphoid stress fractures have been reported in young male athletes, with 14 male and only 2 female patients reported in the available literature. The exact mechanism for this apparent gender discrepancy remains unclear but may be related to males reaching skeletal maturity at a later age than females, as adolescence appears to be a risk factor for suffering a scaphoid stress fracture. Similarly, while a direct link to age, sex, and athletic participation remains speculative, scaphoid stress fractures may be in part due to more intense participation in higher-level, longerduration athletic training during adolescence.

Importantly, many of the published case reports regarding scaphoid stress fractures have noted a delay in diagnosis with this injury, with the majority of cases being recognized only after the fracture became apparent on plain radiographs $[2,3,5]$. Several case reports obtained bone scans to aid in their diagnosis of a scaphoid stress fracture [2-4], but more recently advanced imaging such as MRI and/or CTs 


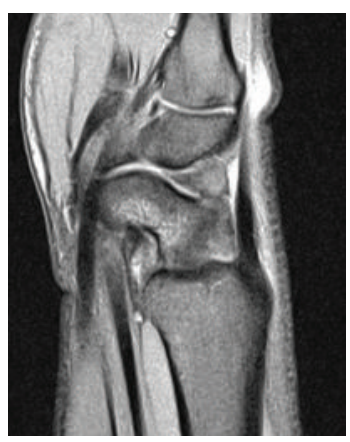

(a)

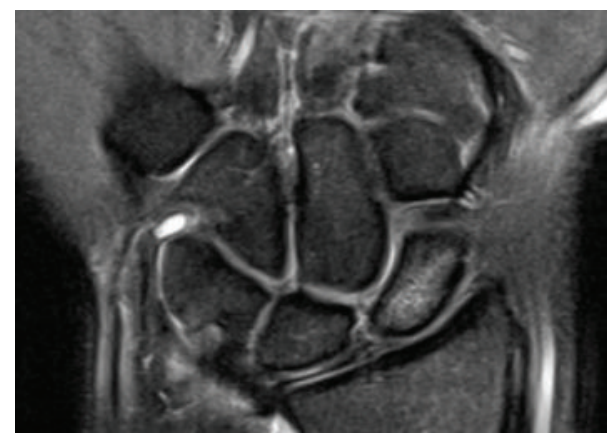

(b)

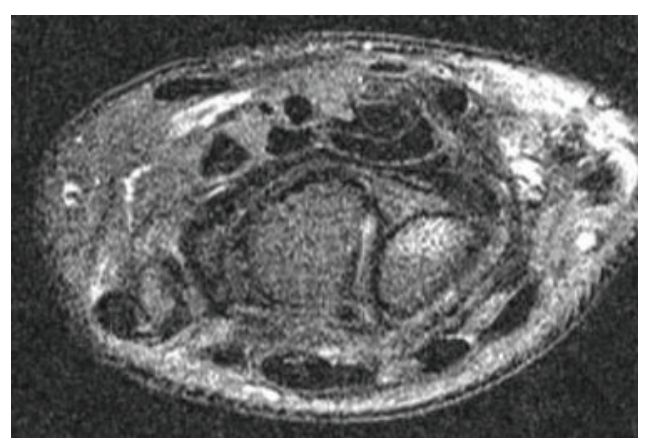

(c)

FIGURE 4: (a) A 1.5-Tesla MRI T2 sagittal cut demonstrating palmar scaphoid waist bone edema consistent with incomplete scaphoid waist stress fracture obtained at the time of initial presentation. (b) A 1.5-Tesla MRI T2 coronal cut showing scaphoid waist bone edema consistent with incomplete scaphoid waist stress fracture obtained at the time of initial presentation. (c) A 1.5-Tesla MRI T2 axial cut showing palmar scaphoid waist bone edema consistent with incomplete scaphoid waist stress fracture obtained at the time of initial presentation.

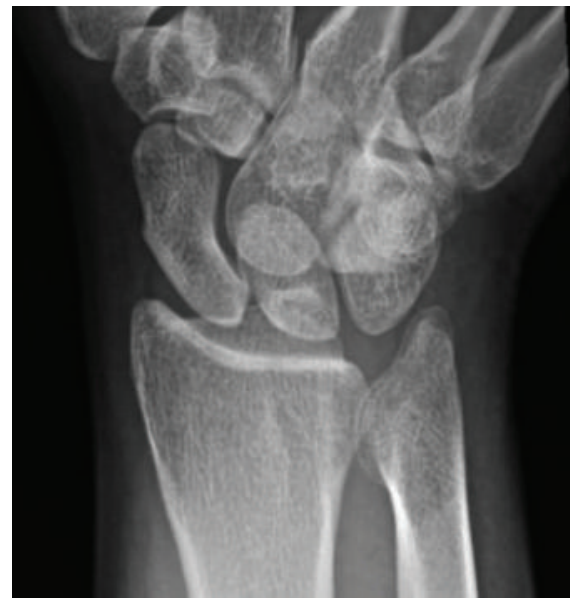

FIGURE 5: A scaphoid view obtained 6 weeks after presentation without radiographic evidence of a scaphoid waist fracture.

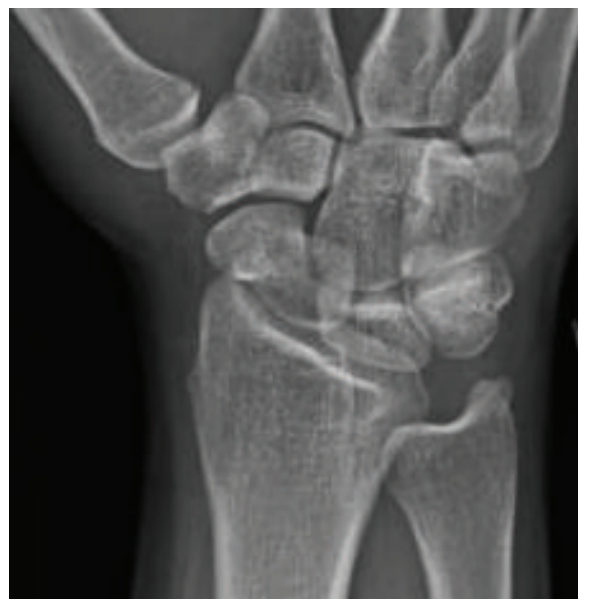

FIGURE 6: An oblique radiographic view obtained 6 weeks after presentation with no radiographic abnormality of the scaphoid.

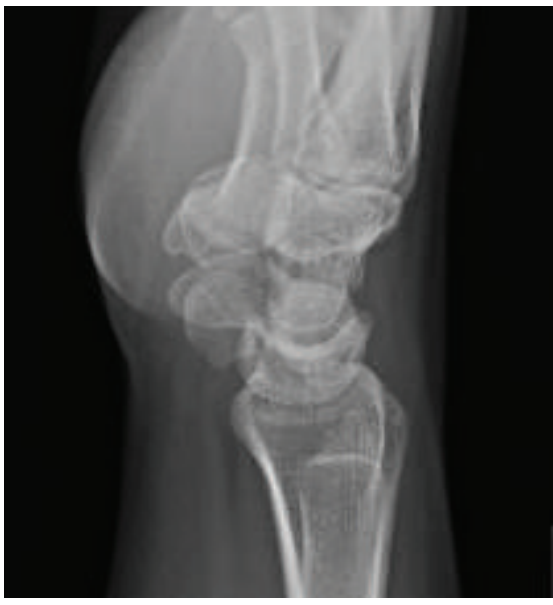

FIGURE 7: A lateral radiographic view obtained at 6 weeks after initial presentation showing a normal appearing scaphoid.

has been utilized to diagnose or confirm scaphoid stress fractures $[6,7,11,13,15,16]$. Several patients with negative presenting radiographs had the fracture only later diagnosed on repeat radiographs or advanced imaging $[2,3,6]$. In the case presented here, the presenting radiographs were negative, and an MRI was essential for making the diagnosis.

There are no current guidelines specific to the treatment of scaphoid stress fractures. However, for displaced or chronic scaphoid fractures or nonunions, surgical intervention is typically recommended. For nondisplaced or incomplete fractures, as in this case, nonsurgical treatment with immobilization is usually appropriate. Of the cases described in the literature, nine of the cases were treated nonoperatively $[2,3$, $5,9,15,16]$, two cases were initially treated nonoperatively but their patients had ongoing pain and evidence of nonunion requiring surgical intervention $[6,10]$, and five cases were treated with open reduction and internal fixation [7, 11-13]. For all patients treated with surgery, either a Herbert screw 
TABLE 1: Clinical characteristics, imaging evaluation, and treatment method for scaphoid stress fractures published in the literature.

\begin{tabular}{|c|c|c|c|c|c|c|c|c|}
\hline Author & Sport & $\begin{array}{c}\text { Age } \\
\text { (years)/ } \\
\text { gender }\end{array}$ & Laterality & $\begin{array}{c}\text { Pain } \\
\text { duration }\end{array}$ & $\begin{array}{c}\text { Time to } \\
\text { diagnosis after } \\
\text { presentation }\end{array}$ & $\begin{array}{l}\text { Imaging } \\
\text { presentation }\end{array}$ & Treatment & $\begin{array}{l}\text { Scaphoid } \\
\text { fracture } \\
\text { location }\end{array}$ \\
\hline $\begin{array}{l}\text { Manzione and } \\
\text { Pizzutillo [2] }\end{array}$ & Gymnast & $16 \mathrm{M}$ & Left & 6 weeks & 2 weeks & $\begin{array}{c}\text { Negative XR; } \\
\text { positive bone scan }\end{array}$ & $\begin{array}{c}\text { Thumb spica cast } \\
\times 10 \text { weeks }\end{array}$ & Waist \\
\hline \multirow{4}{*}{ Hanks et al. [3] } & Shot-putter & $19 \mathrm{M}$ & Right & 1.5 years & 2 months & $\begin{array}{l}\text { Negative initial XR; } \\
\text { positive repeat XR } \\
\text { at } 2 \text { months }\end{array}$ & $\begin{array}{c}\text { Thumb spica } \\
\text { cast/splint } \times 11 \\
\text { weeks }\end{array}$ & Waist \\
\hline & \multirow[t]{2}{*}{ Gymnast* } & \multirow[t]{2}{*}{$18 \mathrm{M}$} & Left & 2 years & 1 year, 2 weeks & $\begin{array}{c}\text { Positive XR; } \\
\text { positive bone scan } \\
\text { prior to XR }\end{array}$ & $\begin{array}{l}\text { Thumb spica cast } \\
\times 4 \text { months }\end{array}$ & Waist \\
\hline & & & Right & 3 weeks & No delay & $\begin{array}{l}\text { Positive bone scan; } \\
\text { negative XR }\end{array}$ & $\begin{array}{l}\text { Thumb spica cast } \\
\times 6 \text { weeks }\end{array}$ & Waist \\
\hline & Gymnast & $18 \mathrm{M}$ & Left & 2 months & No delay & $\begin{array}{c}\text { Positive bone scan; } \\
\text { negative XR }\end{array}$ & $\begin{array}{c}\text { Thumb spica cast } \\
\times 6 \text { weeks }\end{array}$ & Waist \\
\hline $\begin{array}{l}\text { Engel and } \\
\text { Feldner-Busztin } \\
{[4]}\end{array}$ & Gymnast & $18 \mathrm{M}$ & Bilateral & 1 year & Not mentioned & $\begin{array}{l}\text { Positive bone scan } \\
\text { \& XR }\end{array}$ & Not mentioned & Waist \\
\hline $\begin{array}{l}\text { Inagaki and Inoue } \\
\text { [9] }\end{array}$ & Badminton & $16 \mathrm{M}$ & Right & 7 weeks & No delay & Positive XR & $\begin{array}{c}\text { Thumb spica cast } \\
\times 8 \text { weeks }\end{array}$ & Waist \\
\hline $\begin{array}{l}\text { Matzkin and } \\
\text { Singer [5] }\end{array}$ & Gymnast & $13 \mathrm{~F}$ & Right & 3 months & 3 months & $\begin{array}{c}\text { Negative initial XR; } \\
\text { positive XR } 3 \\
\text { months later }\end{array}$ & $\begin{array}{c}\text { Long arm spica } \times 8 \\
\text { weeks, short arm } \\
\text { thumb spica } \times 4 \\
\text { weeks }\end{array}$ & Waist \\
\hline $\begin{array}{l}\text { Brutus and } \\
\text { Chahidi [10] }\end{array}$ & Badminton & $23 \mathrm{M}$ & Right & 8 weeks & No delay & Positive XR & $\begin{array}{l}\text { Thumb spica cast } \\
\times 8 \text { weeks and then } \\
\text { ORIF: Herbert } \\
\text { screw \& graft }\end{array}$ & Waist \\
\hline Hosey et al. [11] & Diver & $13 \mathrm{~F}$ & Right & 2 months & No delay & $\begin{array}{c}\text { Positive XR; } \\
\text { confirmed on MRI }\end{array}$ & $\begin{array}{c}\text { ORIF: Herbert } \\
\text { screw }\end{array}$ & Waist \\
\hline Rethnam et al. [12] & Cricketer & $38 \mathrm{M}$ & Right & 2 years & No delay & Positive XR & $\begin{array}{l}\text { ORIF: Herbert } \\
\text { screw \& graft }\end{array}$ & Waist \\
\hline Yamagiwa et al. [6] & Gymnast & $18 \mathrm{M}$ & Right & $\begin{array}{c}\text { Not } \\
\text { mentioned }\end{array}$ & No delay & $\begin{array}{c}\text { Positive MRI; } \\
\text { negative XR }\end{array}$ & $\begin{array}{l}\text { Thumb spica cast } \\
\times 8 \text { weeks and then } \\
\text { ORIF: Herbert } \\
\text { screw }\end{array}$ & Waist \\
\hline Nakamoto et al. [7] & ] Gymnast & $18 \mathrm{M}$ & Right & 3 months & No delay & $\begin{array}{c}\text { Positive XR; } \\
\text { confirmed on MRI }\end{array}$ & $\begin{array}{c}\text { ORIF: Herbert } \\
\text { screw }\end{array}$ & Waist \\
\hline Pidemunt et al. [13] & Goalkeeper & $13 \mathrm{M}$ & Bilateral & 2 years & No delay & $\begin{array}{c}\text { Positive XR; } \\
\text { confirmed on CT }\end{array}$ & $\begin{array}{l}\text { ORIF: graft \& } \\
\text { Herbert screw }\end{array}$ & Waist \\
\hline $\begin{array}{l}\text { Mohamed Haflah } \\
\text { et al. [14] }\end{array}$ & Diver & $16 \mathrm{M}$ & Bilateral & $\begin{array}{l}18 \text { months } \\
\text { (right) }\end{array}$ & $\begin{array}{l}1 \text { year (right), no } \\
\text { delay (left) }\end{array}$ & $\begin{array}{l}\text { Positive XR R wrist } \\
\text { (nonunion); } \\
\text { incidental positive } \\
\text { XR L wrist }\end{array}$ & $\begin{array}{l}\text { ORIF: headless } \\
\text { compression screw } \\
\text { \& graft }\end{array}$ & Waist \\
\hline Saglam et al. [15] & Goalkeeper & $19 \mathrm{M}$ & Bilateral & 4 years & No delay & $\begin{array}{c}\text { Positive XR; } \\
\text { confirmed on MRI }\end{array}$ & $\begin{array}{c}\text { Thumb spica cast } \\
\times 12 \text { weeks }\end{array}$ & Waist \\
\hline Kohyama et al. [16] & Tennis & $18 \mathrm{M}$ & Right & 4 months & No delay & $\begin{array}{c}\text { Positive XR; } \\
\text { confirmed on CT } \\
\text { \& MRI } \\
\end{array}$ & $\begin{array}{c}\text { Thumb spica } \\
\text { cast/splint } \times 12 \\
\text { weeks }\end{array}$ & Waist \\
\hline $\begin{array}{l}\text { Kohring et al. } \\
\text { (current report) }\end{array}$ & Shot-putter & $22 \mathrm{~F}$ & Right & 2 months & No delay & $\begin{array}{l}\text { Negative XR; } \\
\text { positive MRI }\end{array}$ & $\begin{array}{c}\text { Thumb spica splint } \\
\times 6 \text { weeks }\end{array}$ & Waist \\
\hline
\end{tabular}

${ }^{*}$ Same patient with two different presentations. 
or a headless compression screw was used with the majority of cases also using bone autograft [6, 7, 10-13]. All patients reported had successful treatment outcomes regardless of the intervention with return to athletic activities and no reports of recurrence of pain, reinjury, nonunion, or malunion at longer-term follow-up.

In summary, stress fractures of the scaphoid are exceedingly rare but potentially devastating if not recognized and treated promptly. Clinicians should have a high index of suspicion when evaluating an athlete or patient who presents with an insidious onset of activity-related wrist pain and snuffbox tenderness and who is involved in a sport that requires repetitive loaded wrist extension. While the majority of cases described have involved male athletes, scaphoid stress fractures also occur in females. A low-threshold to obtain advanced imaging when radiographs appear negative for scaphoid pathology may aid in the early diagnosis of this rare entity, avoid fracture nonunion, and reduce the need for complex surgical intervention.

\section{Competing Interests}

The authors declare that there are no competing interests regarding the publication of this paper.

\section{References}

[1] R. L. Linscheid and J. H. Dobyns, "Athletic injuries of the wrist," Clinical Orthopaedics and Related Research, vol. 198, pp. 141-151, 1985.

[2] M. Manzione and P. D. Pizzutillo, "Stress fracture of the scaphoid waist: a case report," The American Journal of Sports Medicine, vol. 9, no. 4, pp. 268-269, 1981.

[3] G. A. Hanks, A. Kalenak, L. S. Bowman, and W. J. Sebastianelli, "Stress fractures of the carpal scaphoid: a report of four cases," The Journal of Bone \& Joint Surgery-American Volume, vol. 71, no. 6, pp. 938-941, 1989.

[4] A. Engel and H. Feldner-Busztin, "Bilateral stress fracture of the scaphoid: a case report," Archives of Orthopaedic and Trauma Surgery, vol. 110, no. 6, pp. 314-315, 1991.

[5] E. Matzkin and D. I. Singer, "Scaphoid stress fracture in a 13year-old gymnast: a case report," Journal of Hand Surgery, vol. 25, no. 4, pp. 710-713, 2000.

[6] T. Yamagiwa, H. Fujioka, H. Okuno et al., "Surgical treatment of stress fracture of the scaphoid of an adolescent gymnast," Journal of Sports Science and Medicine, vol. 8, no. 4, pp. 702704, 2009.

[7] J. C. Nakamoto, M. Saito, G. Medina, and B. Schor, "Scaphoid stress fracture in high-level gymnast: a case report," Case Reports in Orthopedics, vol. 2011, Article ID 492407, 3 pages, 2011.

[8] C. M. Coady and L. J. Micheli, "Stress fractures in the pediatric athlete," Clinics in Sports Medicine, vol. 16, no. 2, pp. 225-238, 1997.

[9] H. Inagaki and G. Inoue, "Stress fracture of the scaphoid combined with the distal radial epiphysiolysis," British Journal of Sports Medicine, vol. 31, no. 3, pp. 256-257, 1997.

[10] J. P. Brutus and N. Chahidi, "Could this unusual scaphoid fracture occurring in a badminton player be a stress fracture?" Chirurgie de la Main, vol. 23, no. 1, pp. 52-54, 2004.
[11] R. G. Hosey, J. M. Hauk, and M. R. Boland, "Scaphoid stress fracture: an unusual cause of wrist pain in a competitive diver," Orthopedics, vol. 29, no. 6, pp. 503-505, 2006.

[12] U. Rethnam, R. S. U. Yesupalan, and T. M. Kumar, "Non union of scaphoid fracture in a cricketer-possibility of a stress fracture: a case report," Journal of Medical Case Reports, vol. 1, article 37, 2007.

[13] G. Pidemunt, R. Torres-Claramunt, A. Ginés, S. De Zabala, and J. Cebamanos, "Bilateral stress fracture of the carpal scaphoid: report in a child and review of the literature," Clinical Journal of Sport Medicine, vol. 22, no. 6, pp. 511-513, 2012.

[14] N. H. Mohamed Haflah, N. F. Mat Nor, S. Abdullah, and J. Sapuan, "Bilateral scaphoid stress fracture in a platform diver presenting with unilateral symptoms," Singapore Medical Journal, vol. 55, no. 10, pp. e159-e161, 2014.

[15] F. Saglam, D. Gulabi, Ö. Baysal, H. I. Bekler, Z. Tasdemir, and N. Elmali, "Chronic wrist pain in a goalkeeper; Bilateral scaphoid stress fracture: a case report," International Journal of Surgery Case Reports, vol. 7, pp. 20-22, 2015.

[16] S. Kohyama, A. Kanamori, T. Tanaka, Y. Hara, and M. Yamazaki, "Stress fracture of the scaphoid in an elite junior tennis player: a case report and review of the literature," Journal of Medical Case Reports, vol. 10, no. 1, article 8, 2016.

[17] E. R. Weber and E. Y. Chao, "An experimental approach to the mechanism of scaphoid waist fractures," Journal of Hand Surgery, vol. 3, no. 2, pp. 142-148, 1978.

[18] M. Majima, E. Horii, H. Matsuki, H. Hirata, and E. Genda, "Load transmission through the wrist in the extended position," Journal of Hand Surgery, vol. 33, no. 2, pp. 182-188, 2008. 


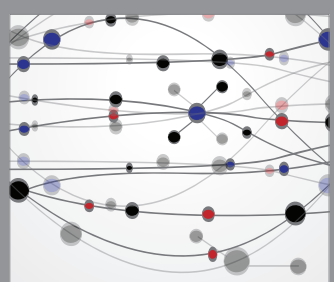

The Scientific World Journal
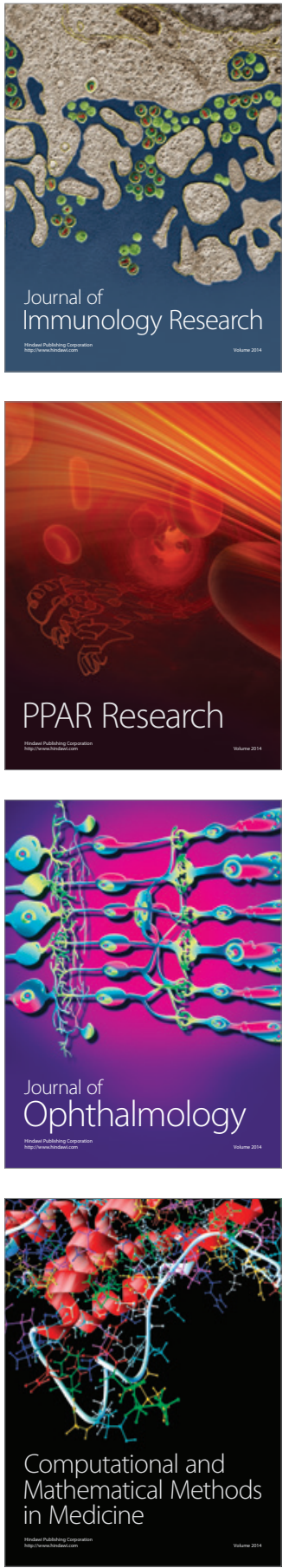

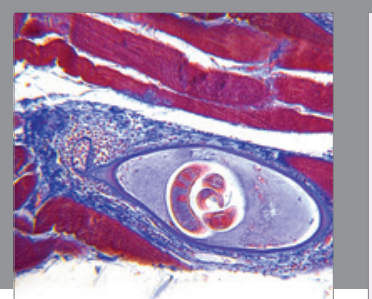

Gastroenterology Research and Practice

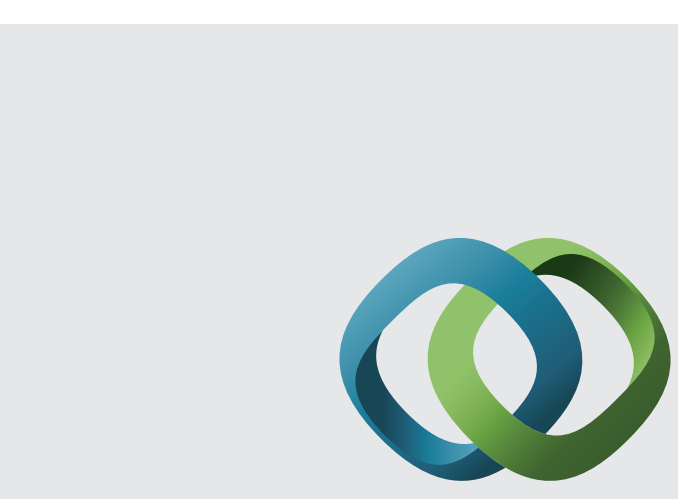

\section{Hindawi}

Submit your manuscripts at

http://www.hindawi.com
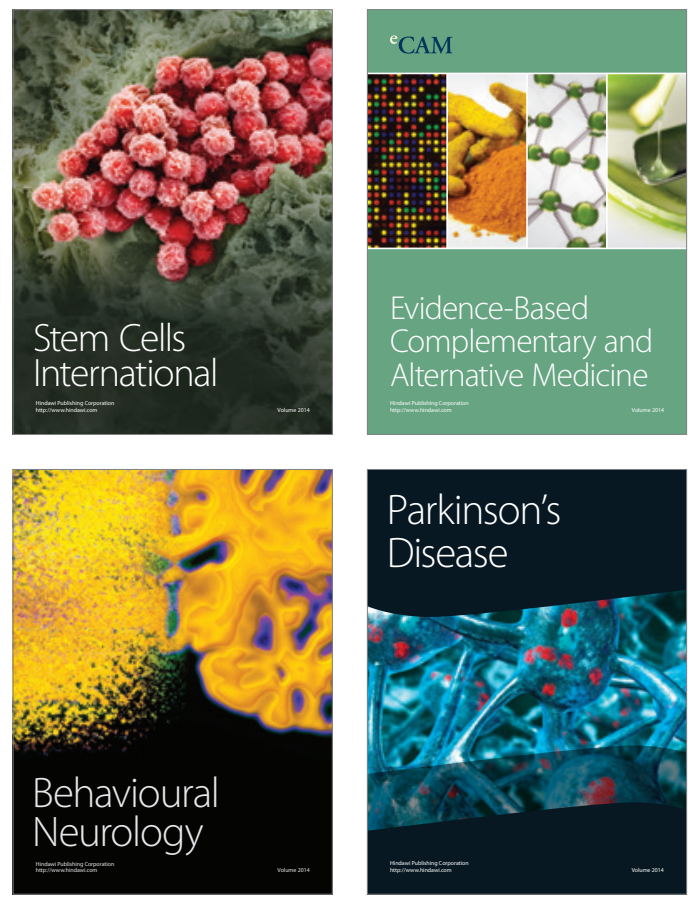
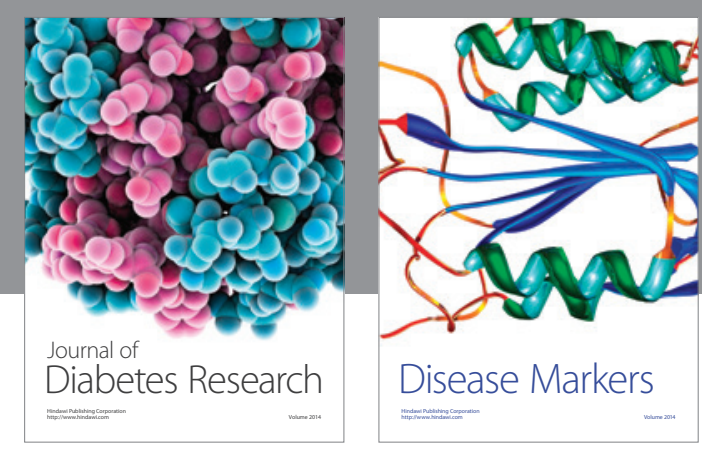

Disease Markers
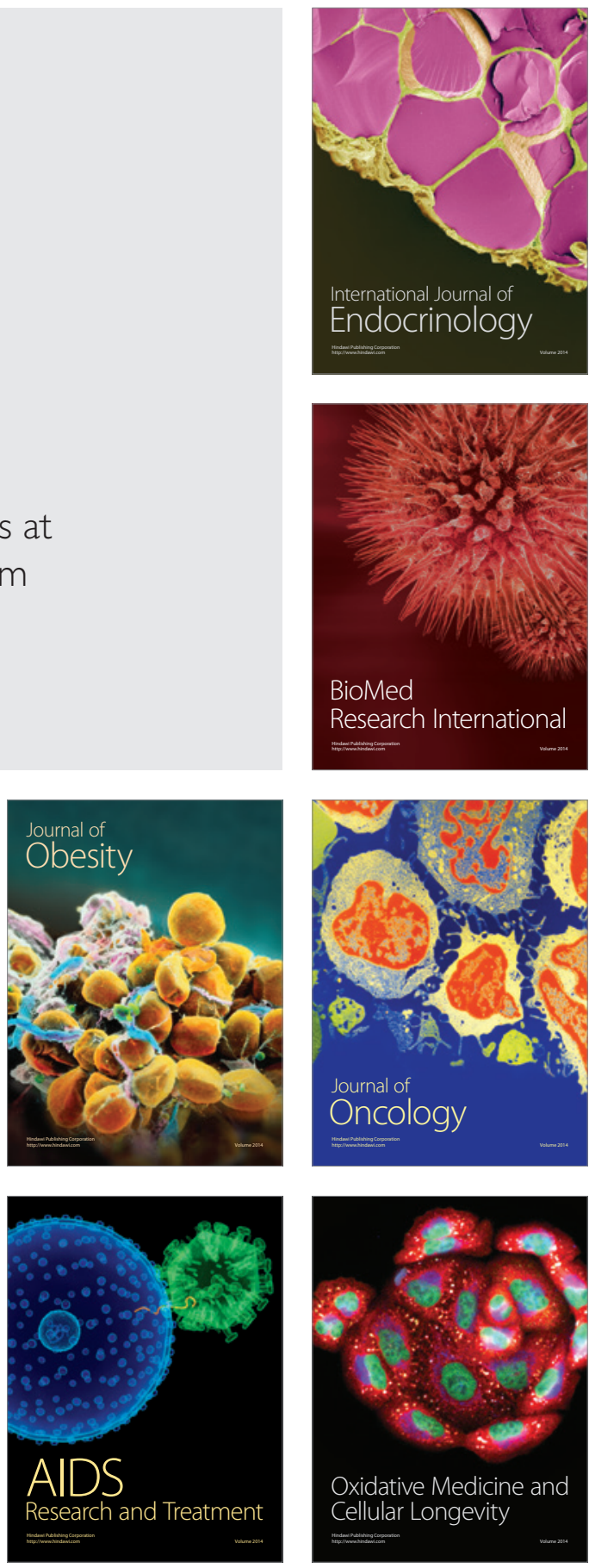